\title{
Genomic merit for reproductive traits. II: Physiological responses of Holstein heifers
}

\author{
Anderson Veronese, ${ }^{1}$ Odinei Marques, ${ }^{1}$ Francisco Peñagaricano, ${ }^{2}$ Rafael S. Bisinotto, ${ }^{1}$ Ky G. Pohler, ${ }^{3}$ \\ Todd R. Bilby, ${ }^{4}$ and Ricardo C. Chebel ${ }^{1,2 *}$

\section{ABSTRACT}

Fertility traits were recently added to the evaluation of genetic merit, allowing for the selection of Holstein cattle with improved reproductive performance. In the current study, we investigated the associations among genomic merit for daughter pregnancy rate (GDPR) and heifer conception rate (GHCR) and physiological responses during proestrus and diestrus. Holstein heifers $(\mathrm{n}=99)$ were classified based on GDPR [high $=$ $3.26 \pm 0.76$ (1.6 to 5.3), $\mathrm{n}=48$; low $=-0.17 \pm 0.75$ $(-1.8$ to 1.0$), \mathrm{n}=51]$ and GHCR [high $=2.75 \pm 0.77$ (1.5 to 5.5$), \mathrm{n}=49$; low $=0.06 \pm 0.67$ ( -2.1 to 1.2 ), $\mathrm{n}=50]$. Heifers were fitted with an automated estrous detection device, were treated with $\mathrm{PGF}_{2 \alpha}$ for synchronization of estrus, and received either artificial insemination or embryo transfer at detected estrus. Blood was sampled at the time of $\mathrm{PGF}_{2 \alpha}$ treatment, within $24 \mathrm{~h}$ of the onset of estrus (d 0), and on d 7, 14, $19 \pm 2,28$, and 35. Blood samples from all heifers were analyzed for concentrations of estradiol (d 0) and progesterone (on the day of $\mathrm{PGF}_{2 \alpha}$ treatment and $\mathrm{d} 0,7$, and 14). Blood samples from heifers pregnant on $\mathrm{d} 38 \pm 3$ were analyzed for concentrations of progesterone (d 0, 7, 14, $19 \pm 2,28$, and 35), pregnancy-specific protein B (d $19 \pm 2,28$, and 35), and insulin-like growth factor 1 (d 0, 7, 14, $19 \pm 2,28$, and 35). Expression of mRNA for interferon-stimulated gene 15 in peripheral leukocytes isolated from blood collected on d $19 \pm 2$ was determined. Ovaries were scanned by ultrasound daily from d 0 to 4 or until ovulation was detected. Heifers with low GHCR tended to be less likely to be detected in estrus (78.0 vs. 91.8\%). Estradiol concentration on d 0 was greater for heifers with high GDPR (4.53 \pm 0.23 vs. $3.79 \pm 0.23 \mathrm{pg} / \mathrm{mL}$ ). The ovulatory follicle was larger for heifers with high GDPR (16.28 \pm 0.33 vs.

Received June 19, 2018.

Accepted September 24, 2018.

*Corresponding author: rcchebel@ufl.edu
$14.55 \pm 0.35 \mathrm{~mm}$ ), whereas heifers with high GHCR tended to have smaller ovulatory follicles $(15.00 \pm 0.31$ vs. $15.83 \pm 0.37 \mathrm{~mm})$. Heifers with high GDPR tended to be more likely to ovulate within $96 \mathrm{~h}$ of the onset of estrus (90.7 vs. $75.0 \%$ ). Among heifers pregnant on d $38 \pm 3$, GDPR and GHCR were not associated with mRNA expression for interferon-stimulated gene 15 . Heifers with high GDPR had greater concentration of pregnancy-specific protein B from d 28 to 35 (3.03 \pm 0.15 vs. $2.48 \pm 0.1 \mathrm{ng} / \mathrm{mL}$ ). Heifers with high GHCR tended to have greater insulin-like growth factor 1 concentration from d 7 to $35(108.0 \pm 3.2$ vs. $97.7 \pm 4.2$ $\mathrm{ng} / \mathrm{mL}$ ). Our results suggest that selection for Holstein cattle for GDPR may have positive effects on reproductive performance through changes in ovarian follicle development and steroidogenesis. Although selection of Holstein cattle for GHCR may negatively affect estrous expression by affecting ovarian follicle growth, selection for GHCR may improve reproductive performance by altering the somatotropic axis.

Key words: genomic merit, dairy heifer, reproductive physiology

\section{INTRODUCTION}

Reproductive performance of Holstein cattle has declined over the past decades, with the lowest breeding values for daughter pregnancy rate (DPR) recorded in the early 2000s (AIPL, 2013). The intense genetic selection for milk yield with disregard for reproduction traits is often believed to have negatively affected reproductive performance of Holstein cattle (Lucy, 2001; VanRaden et al., 2004). Between 1963 and 2003 an increment of $3,259 \mathrm{~kg}$ in breeding values for milk yield (AIPL, 2005) was observed; concurrently, breeding values for DPR decreased from approximately 16 in 1957 to negative values in the early 2000s (USDA, 2016). To halt the decline in reproductive performance in the Holstein cattle population, DPR was added to the genetic merit in 2004 (VanRaden et al., 2004). Since the 
addition of DPR to the genetic merit, breeding values for DPR have slightly increased, but they remain lower than the DPR values observed in the 1960s.

Genetic progress for reproductive traits has been slow (García-Ruiz et al., 2016) because of their low heritability (Pryce et al., 2004). With recent advances in genomic tools for prediction of breeding values and inclusion of genomic merit for DPR (GDPR) and heifer conception rate (GHCR) in selection programs, genetic progress for these low-heritability traits has significantly increased (García-Ruiz et al., 2016). Daughter pregnancy rate is a measure of the hazard of pregnancy of a bull's daughter compared with the population (AIPL, 2013), and an increase in 1 point in the GDPR of a population of lactating cows is expected to result in a reduction in the interval from calving to pregnancy of approximately $4 \mathrm{~d}$ (Santos et al., 2010). Heifer conception rate (HCR) is a measure of the likelihood of pregnancy following a service for a bull's daughter compared with the population (AIPL, 2013). Genomic merit for fertility traits is associated with genes implicated in different reproductive pathways in the Holstein population (Ortega et al., 2016; Mikshowsky et al., 2017). Cochran et al. (2013) and Ortega et al. (2016) demonstrated significant associations between DPR and HCR values and SNP within or near genes involved with the endocrine system, cell signaling, immune function, inhibition of apoptosis, and steroidogenesis. A paucity of data exists, however, regarding the physiological differences between Holstein cattle with differing genomic merit for fertility traits commonly used in current genomic selection programs.

Recent studies have indicated that selection for DPR and HCR may affect reproductive physiological markers and pathways. Single nucleotide polymorphisms within or near genes involved in steroidogenesis and regulated by steroids were overexpressed in bulls with high DPR (Cochran et al., 2013; Ortega et al., 2016). Cummins et al. (2012a) noted that progesterone (P4) concentration was greater during diestrus among cows with high versus low genetic merit for fertility traits. Furthermore, cows with lower genetic merit for fertility traits had reduced IGF-1 concentration during lactation and upregulation of hepatic mRNA expression for IGF binding proteins 2, 5, and 6 around parturition compared with cows with high genetic merit for fertility traits (Cummins et al., 2012b). Thus, it seems plausible that heifers with differing GDPR and GHCR could have different concentrations of estradiol, P4, and IGF-1. Increased expression of mRNA for interferon-stimulated gene 15 (IS G15) by peripheral leukocytes has been associated with improved embryo and fetal development (Matsuyama et al., 2012; Ribeiro et al., 2014) and has been considered a marker for increased secretion of
IFN- $\tau$ by the trophoblast (reviewed by Dorniak et al., 2013). Similarly, pregnancy-specific protein B (PSPB), secreted by binucleate trophoblastic cells, is associated with conceptus development and pregnancy in heifers and cows (Humblot et al., 1988; Green et al., 2005). Therefore, by determining IFN- $\tau$ and PSPB, we may be able to indirectly detect differences in growth of conceptus of heifers with differing GDPR and GHCR.

The hypotheses of the current study were that GDPR and GHCR are associated with increased concentrations of steroidal hormones during the proestrus and diestrus, that heifers with greater GDPR and GHCR will have greater IGF-1 concentrations during diestrus, and that conceptus growth will be greater for heifers with greater GDPR and GHCR. Therefore, the objectives of the current study were to determine the differences in estradiol concentration on d 0; ovulatory follicle size; concentrations of P4, IGF-1, and PSPB during diestrus; and expression of mRNA for ISG15 after estrus among heifers with differing GDPR and GHCR.

\section{MATERIALS AND METHODS}

All procedures involving animals were approved by the animal care and use committee of the University of Florida (protocol no. 201609559).

\section{Animals, Housing, and Management}

Heifers used in the current study are a subset of heifers used in a larger study (Veronese et al., 2019) conducted in a commercial dairy herd with approximately 4,200 replacement heifers located in north central Florida from March to December of 2016. A total of 1,019 heifers were enrolled in the study between 10 and 11 mo of age. Of these, 1,005 were genotyped within 2 mo of birth using a 50k SNP platform that is commercially available (Clarifide, Zoetis, Parsippany, NJ). For the purpose of this study, data referent to genomic breeding values for DPR and HCR recorded within 2 mo of birth were used. Heifers selected for this study were in the top and bottom 25th percentiles for GDPR and GHCR values in the population of 1,005 heifers used in a companion study (Veronese et al., 2019). Therefore, there were 48 heifers with high GDPR, 51 heifers with low GDPR, 49 heifers with high GHCR, and 50 heifers with low GHCR (Table 1$)$. The reliabilities $( \pm$ SEM) for GDPR and GHCR in the study population were $67.3 \pm$ $0.06 \%$ and $58.9 \pm 0.14 \%$, respectively.

\section{Automated Estrous Monitoring Device}

At enrollment, an automated estrous detection monitoring device (Heat Rumination Long Distance, 
Table 1. Descriptive data of the study population in regard to genomic merit for daughter pregnancy rate $(\mathrm{GDPR})$ and genomic merit for heifer conception rate $(\mathrm{GHCR})^{1}$

\begin{tabular}{|c|c|c|c|c|c|}
\hline \multirow[b]{2}{*}{ Item } & \multirow[b]{2}{*}{$\mathrm{n}$} & \multicolumn{2}{|c|}{ GDPR } & \multicolumn{2}{|c|}{ GHCR } \\
\hline & & Mean $( \pm \mathrm{SD})$ & Range & Mean $( \pm \mathrm{SD})$ & Range \\
\hline High GDPR & 48 & $3.26 \pm 0.76$ & $1.60,5.30$ & $2.03 \pm 1.40$ & $-0.10,5.50$ \\
\hline Low GDPR & 51 & $-0.17 \pm 0.75$ & $-1.80,1.00$ & $0.80 \pm 1.42$ & $-2.10,3.30$ \\
\hline High GHCR & 49 & $2.15 \pm 1.76$ & $-1.80,5.30$ & $2.75 \pm 0.77$ & $1.50,5.50$ \\
\hline Low GHCR & 50 & $0.85 \pm 1.78$ & $-1.80,4.20$ & $0.06 \pm 0.67$ & $-2.10,1.20$ \\
\hline
\end{tabular}

${ }^{1}$ Heifers were genotyped within 2 mo of birth using a 50k SNP platform that is commercially available (Clarifide, Zoetis, Parsippany, NJ). Data referent to genomic breeding values for daughter pregnancy rate and heifer conception rate recorded within 2 mo of birth were used. Reliabilities $( \pm \mathrm{SEM})$ for GDPR and GHCR in the study population were $67.3 \pm 0.06 \%$ and $58.9 \pm 0.14 \%$, respectively.

SCR Inc., Netanya, Israel) was fitted on the left cranial area of the neck of all heifers. The monitoring device determined activity through an accelerometer and rumination based on sounds of regurgitation and mastication through a microphone. Activity and rumination data were recorded for every 2 -h period. Estrus was determined according to changes in patterns of activity and rumination within a 2 -h period compared with the average activity and rumination of the same period in the previous 5 and $7 \mathrm{~d}$, respectively (DataFlow2, SCR Inc.).

\section{Reproductive Management}

From enrollment to the start of the reproductive program, all spontaneous estrus events were recorded. Once weekly, heifers eligible to start the reproductive program $(\geq 12$ mo of age and $\geq 340 \mathrm{~kg}$ of live BW) were classified according to estrous cycle phase into metestrus (d 0 to 3 ), early diestrus (d 4 to 6 ), mid diestrus (d 7 to 12), late diestrus (d 13 to 17 ), proestrus (d 18 to 23 ), and unknown ( $\mathrm{d} \geq 24$ or no estrus recorded). Heifers in early diestrus, mid diestrus, and proestrus and heifers that had no recorded estrus were treated with $\mathrm{PGF}_{2 \alpha}$ (cloprostenol sodium, Estrumate, Merck Animal Health, Madison, NJ; or dinoprost tromethamine, Lutalyse, Zoetis Animal Health, Parsippany, NJ) on the same day, and heifers in metestrus were treated with $\mathrm{PGF}_{2 \alpha} 96 \mathrm{~h}$ later (estrous cycle d 4 to 7 ). Only heifers treated with cloprostenol sodium were used in the current study. According to the genetic selection program of the dairy, heifers were selected to be artificially inseminated on the same morning of detected estrus or to receive an embryo (embryo transfer) 6 to $9 \mathrm{~d}$ after detected estrus (d 0).

\section{Pregnancy Diagnoses and Reproductive Data}

All heifers were examined for pregnancy by palpation per rectum of uterine contents on $\mathrm{d} 38 \pm 3$. Pregnant heifers were re-examined by palpation per rectum of the uterine contents on $\mathrm{d} 73 \pm 3$. Pregnancy per service was calculated by dividing the number of heifers pregnant on d 38 and $73 \pm 3$ by the number of heifers serviced. Pregnancy loss was calculated by dividing the number of heifers not pregnant on $\mathrm{d} 73 \pm 3$ by the number of heifers pregnant on d $38 \pm 3$. Data regarding sire of insemination, sire and dam of embryo, service technician, and reproductive outcomes were collected from farm records using the dairy management software PCDART (Dairy Records Management System, Chapel Hill, NC).

\section{Blood Sampling and Ultrasonography of the Ovaries}

Blood was sampled on the day of $\mathrm{PGF}_{2 \alpha}$ treatment and on $\mathrm{d} 0,7,14,19 \pm 2,28$, and 35. Blood samples after d 14 were not collected from heifers that returned to estrus following the first service. Blood was sampled by puncture of the coccygeal vein or artery into evacuated tubes containing K2 EDTA (Vacutainer, Becton Dickinson, Franklin Lakes, NJ). Immediately upon collection, tubes were placed on ice and were transported to the laboratory for processing within 2 to $3 \mathrm{~h}$ of collection. Blood tubes were centrifuged at 1,500 $\times g$ for $15 \mathrm{~min}$ at room temperature. Aliquots of plasma were frozen at $-80^{\circ} \mathrm{C}$ until assayed. Ovaries of heifers were evaluated by transrectal ultrasonography (MyLab, Esaote North America Inc., Fishers, IN) starting on d 0 and daily thereafter until ovulation was characterized (disappearance of a follicle $\geq 10 \mathrm{~mm}$ ) or $96 \mathrm{~h}$ after the onset of estrus.

\section{Hormone and PSPB Assays}

Progesterone concentrations were determined by RIA using a commercial kit (Coat-a-Count, MP Biomedical LLC, Solon $\mathrm{OH}$ ). Plasma harvested from heifers on $\mathrm{d}$ $4(\sim 1 \mathrm{ng} / \mathrm{mL})$ and $10(\sim 4 \mathrm{ng} / \mathrm{mL})$ of the estrous cycle was incorporated into each assay and used to calculate 
the coefficient of variation $(\mathbf{C V})$. Intra- and interassay CV were 5.8 and $10.5 \%$, respectively. Heifers that had $\mathrm{P} 4$ concentration $<1 \mathrm{ng} / \mathrm{mL}$ on $\mathrm{d} 0$ and $\mathrm{P} 4$ concentration $\geq 1 \mathrm{ng} / \mathrm{mL}$ on $\mathrm{d} 7$ were considered to have ovulated. Serum concentration of estradiol-17 $\beta$ was quantified by RIA as described by Jinks et al. (2013). Intra-assay CV for estradiol assays was $2.73 \%$. Concentrations of PSPB were analyzed using a commercially available quantitative ELISA assay (BioPRYN; BioTracking LLC, Moscow, ID) according to the method described by Humblot et al. (1988). Intra- and interassay CV were 3.5 and $8.2 \%$, respectively. Concentrations of IGF-1 were determined by a commercial ELISA kit (Quantikine ELISA Human IGF-1 Immunoassay, R\&D Systems, Minneapolis, MN) designed for human IGF-1 with $100 \%$ cross-reactivity with bovine IGF-1 (Ribeiro et al., 2014), and the intra-assay CV was $8.0 \%$.

\section{Isolation of Peripheral Blood Leukocytes, mRNA Extraction, and Quantitative Real-Time PCR}

Blood sampled on d $19 \pm 2$ was used for isolation of peripheral blood leukocytes according to Gifford et al. (2008). After centrifugation and harvest of plasma, buffy coat fractions were collected by pipetting and transferred to $15-\mathrm{mL}$ conical tubes. A red cell lysis buffer was prepared $\left(150 \mathrm{mM} \mathrm{NH}_{4} \mathrm{Cl}, 10 \mathrm{~m} M \mathrm{NaHCO}_{3}\right.$, and $1 \mathrm{~m} M$ EDTA; pH 7) and added to the buffy coat for a total volume of $15 \mathrm{~mL}$. Tubes were inverted several times and incubated at room temperature for 5 min. Samples were then centrifuged at $300 \times g$ for 10 min at $4^{\circ} \mathrm{C}$, and the supernatant was discarded. The peripheral blood leukocytes pellet was mixed with $5 \mathrm{~mL}$ of red cell lysis buffer, incubated at room temperature for $5 \mathrm{~min}$, and centrifuged at $300 \times g$ for $10 \mathrm{~min}$ at $4^{\circ} \mathrm{C}$, and the supernatant was discarded. The peripheral blood leukocytes pellet was washed with ice-cold PBS and centrifuged at $300 \times g$ for $10 \mathrm{~min}$ at $4^{\circ} \mathrm{C}$, and the supernatant was discarded. The peripheral blood leukocytes pellet was resuspended with $0.8 \mathrm{~mL}$ of Trizol (Molecular Research Center Inc., Cincinnati, OH), transferred to $1.5-\mathrm{mL}$ microtubes, and stored at $-80^{\circ} \mathrm{C}$.
The interval from blood sample collection to peripheral blood leukocytes sample storage at $-80^{\circ} \mathrm{C}$ was $<6 \mathrm{~h}$.

Extraction of mRNA was conducted according to the manufacturer's recommendations for the RNA extraction kit (PureLink RNA Mini Kit; Invitrogen, Carlsbad, CA). The concentration of RNA was calculated by measuring absorbance at $260 \mathrm{~nm}$, and $1 \mu \mathrm{g}$ of total cellular mRNA was treated with DNase (RQ1 RNaseFree DNase; Promega, Madison, WI) and was used to synthesize cDNA using the DyNAmo cDNA Synthesis Kit (Thermo Scientific, Waltham, MA). Complementary DNA was then used for quantitative real-time PCR (ABI 7500 Sequence Detector; Applied Biosystems Inc., Foster City, CA). Three genes were investigated: ISG15 (target gene), $\beta$-actin (ACTB, reference gene), and ribosomal protein L 19 (RPL19, reference gene). Primer reference and sequence are represented in Table 2. Each reaction mixture consisted of $3 \mu \mathrm{L}$ of a 1:5 dilution of the cDNA, gene-specific forward and reverse primers, SYBR Green (Applied Biosystems Inc.), and nucleasefree water in a total reaction volume of $20 \mu \mathrm{L}$. Reactions were run in duplicate and comprised 40 cycles of a 3-step amplification protocol $\left[30 \mathrm{~s}\right.$ at $95^{\circ} \mathrm{C}$ followed by $45 \mathrm{~s}$ at the optimized annealing temperature $\left(57-60^{\circ} \mathrm{C}\right)$ and $1 \mathrm{~min}$ at $72^{\circ} \mathrm{C}$ ]. Primer efficiency ranged from 81 to $85 \%$. Melting curve analysis was also performed to ensure amplification of a single product.

Data are presented using the comparative method developed by Livak and Schmittgen (2001) using nonpregnant low-GDPR and low-GHCR heifers as the reference for comparisons. Relative expression values were obtained by raising the PCR amplification efficiency $(\mathrm{E}=2)$ to the power of the delta-delta threshold cycle (CT) obtained from the $\Delta \mathrm{CT}$ least squares means differences of pairwise comparisons among treatment and reference groups (Yuan et al., 2006). The $\Delta \mathrm{CT}$ values subjected to statistical analysis were generated by normalization of $\mathrm{CT}$ values from target genes with the geometric mean of $\mathrm{CT}$ values from reference genes (Vandesompele et al., 2002). Confidence intervals for graphical representations of relative expression were generated from the lower and upper confidence limits

Table 2. Primer reference and sequences for genes investigated by quantitative real-time PCR

\begin{tabular}{|c|c|c|c|c|}
\hline Target gene & Gene name & NCBI sequence & Primer & Primer sequence \\
\hline$I S G 15$ & Interferon stimulated gene 15 & NM_174366 & $\begin{array}{l}\text { Forward } \\
\text { Reverse }\end{array}$ & 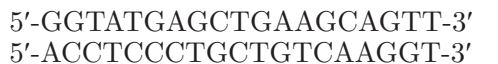 \\
\hline$A C T B^{1}$ & $\beta$-actin & AY141970 & $\begin{array}{l}\text { Forward } \\
\text { Reverse }\end{array}$ & $\begin{array}{l}\text { 5'-CTGGACTTCGAGCAGGAGAT-3' } \\
5^{\prime} \text {-GGATGTCGACGTCACACTTC-3' }\end{array}$ \\
\hline$R P L 19^{1}$ & Ribosomal protein L 19 & NM_001040516 & $\begin{array}{l}\text { Forward } \\
\text { Reverse }\end{array}$ & $\begin{array}{l}\text { 5'-GCGTGCTTCCTTGGTCTTAG-3' } \\
\text { 5'-ATCGATCGCCACATGTATCA-3' }\end{array}$ \\
\hline
\end{tabular}

\footnotetext{
${ }^{1}$ Reference genes.
} 
obtained for $\Delta \mathrm{CT}$ least squares means differences as described by Yuan et al. (2006).

\section{Statistical Analysis}

Data were analyzed using SAS version 9.3 (SAS Institute Inc., Raleigh, NC). Continuous data were analyzed by ANOVA using the MIXED procedure. Data were evaluated for normality and homogeneity of residuals after fitting the model. Data violating the assumption of normality were transformed before analysis. Values referent to the expression of mRNA for ISG15 were transformed to the $\log$ natural function, but data were back-transformed for presentation of results. Otherwise, continuous data were analyzed by a nonparametric procedure (Kruskal-Wallis) using the NPAR1WAY procedure. Dichotomous data were analyzed by logistic regression using the LOGISTIC procedure, but when the event of interest did not occur within one of the classes of an explanatory variable, the data were analyzed by the Fisher's exact test using the FREQ procedure with the Fisher function.

Data from all heifers were used to analyze the association among GDPR and GHCR and estrous cycle day at $\mathrm{PGF}_{2 \alpha}$ treatment, percentage of heifers detected in estrus within $7 \mathrm{~d}$ of $\mathrm{PGF}_{2 \alpha}$ treatment, $\mathrm{P} 4$ concentration on $\mathrm{d} 0$ and from d 7 to 14 , estradiol concentration on d 0 , percentage of heifers ovulating within $96 \mathrm{~h}$ of the onset of estrus based on ultrasound exams, ovulatory follicle diameter, and percentage of heifers ovulating according to changes in $\mathrm{P} 4$ concentration from $\mathrm{d} 0$ to 7. All models included GDPR (high vs. low), GHCR (high vs. low), and the interaction between GDPR and GHCR. The model for evaluating the $\mathrm{P} 4$ concentration on the day of $\mathrm{PGF}_{2 \alpha}$ treatment and the percentage of heifers detected in estrus within $7 \mathrm{~d}$ of $\mathrm{PGF}_{2 \alpha}$ treatment also included estrous cycle day at $\mathrm{PGF}_{2 \alpha}$ treatment. The model for evaluating estradiol concentration on $\mathrm{d} 0$ also included estrous cycle day at $\mathrm{PGF}_{2 \alpha}$ treatment and the interval from onset of estrus to sample collection. The models for evaluating the percentage of heifers ovulating within $96 \mathrm{~h}$ of the onset of estrus based on ultrasound exams, ovulatory follicle diameter, and the percentage of heifers ovulating according to changes in $\mathrm{P} 4$ concentration from d 0 to 7 also included estrous cycle day at $\mathrm{PGF}_{2 \alpha}$ treatment. The model for evaluating the $\mathrm{P} 4$ concentration from d 7 to 14 also included $\mathrm{P} 4$ concentration on $\mathrm{d} 0$, day, the interactions between GDPR and day and between GHCR and day, the type of service (AI or embryo transfer), and the interactions between GDPR and type of service and GHCR and type of service.
Only data from heifers pregnant on $\mathrm{d} 38 \pm 2$ were used for analyses of the association among GDPR and GHCR and concentrations of P4 on d 0 and from $\mathrm{d} 7$ to 35 , IGF- 1 on $\mathrm{d} 0$ and from d 7 to $35, \mathrm{PSPB}$ on d $19 \pm 2$ and from d 28 to 35 , and relative expression of mRNA for ISG15 on d $19 \pm 2$. All models included GDPR (high vs. low), GHCR (high vs. low), the interaction between GDPR and GHCR, the type of service (AI or embryo transfer), and the interactions between GDPR and type of service and GHCR and type of service. The models for evaluating the concentrations of $\mathrm{P} 4$ from $\mathrm{d} 7$ to 35 , IGF-1 from d 7 to 35 , and PSPB from d 28 to 35 also included the respective baseline values (concentrations of P4 on d 0, IGF- 1 on d 0 , and PSPB on d $19 \pm$ 2 ), day, and the interactions between GDPR and day and between GHCR and day.

For each of the statistical models collinearity was tested using the REG procedure of SAS with the "collin" and "VIF" functions. Variables with variance inflation factors $\geq 1.5$ were considered collinear. In such cases, each variable was added to the model separately and the variable with the smallest $P$-value was retained. Variables with $P>0.10$ were removed from the model in a stepwise fashion until only variables with $P \leq 0.10$ remained. Statistical significance was considered at $P$ $\leq 0.05$, and a tendency was considered when $0.05<P$ $\leq 0.10$.

\section{RESULTS}

Descriptive data regarding GDPR and GHCR in the study population are presented in Table 1 . On d $38 \pm$ $3,46.5 \%(20 / 43)$ and $31.0 \%(13 / 42)$ of heifers classified as high and low GDPR, respectively, were pregnant, whereas $46.7 \%(21 / 45)$ and $30.0 \%(12 / 40)$ of heifers classified as high and low GHCR, respectively, were pregnant. Percentages of heifers pregnant on d $73 \pm$ 3 were $44.2 \%(19 / 43)$ and $23.8 \%(10 / 42)$ among heifers classified as high and low GDPR, respectively, and $42.2 \%(19 / 45)$ and $25.0 \%(10 / 40)$ among heifers classified as high and low GHCR, respectively. Finally, 5.0\% $(1 / 20)$ and $23.1 \%(3 / 13)$ of heifers classified as high and low GDPR, respectively, lost pregnancy between d $38 \pm 3$ and $73 \pm 3$, whereas $9.5 \%(2 / 21)$ and $16.7 \%$ $(2 / 12)$ of heifers classified as low and high GHCR, respectively, lost pregnancy between d $38 \pm 3$ and $73 \pm 3$.

\section{Physiological Responses of All Heifers According to GDPR and GHCR}

There were no differences in estrous cycle day at $\mathrm{PGF}_{2 \alpha}$ treatment according to GDPR $(P=0.74)$, 
GHCR $(P=0.24)$, and the interaction between GDPR and GHCR $(P=0.32$; Table 3$)$. The $\mathrm{P} 4$ concentration at $\mathrm{PGF}_{2 \alpha}$ treatment tended $(P=0.08)$ to be higher for heifers with high GDPR but was not different according to GHCR $(P=0.51)$ and the interaction between GDPR and GHCR $(P=0.71$; Table 3$)$. Genomic merit for DPR was not $(P=0.94)$ associated with the likelihood of estrus within $7 \mathrm{~d}$ of $\mathrm{PGF}_{2 \alpha}$ treatment, but heifers with low GHCR were $(P=0.02)$ less likely to be detected in estrus within $7 \mathrm{~d}$ of $\mathrm{PGF}_{2 \alpha}$ treatment (Table $3)$. There was a tendency $(P=0.08)$ for GDPR to be associated with $\mathrm{P} 4$ concentration on d 0 , but GHCR $(P$ $=0.51)$ and the interaction between GDPR and GHCR $(P=0.83)$ were not associated with $\mathrm{P} 4$ concentration on d 0 (Table 3 ). Genomic merit for DPR was $(P=$ $0.03)$ positively associated with estradiol concentration on $\mathrm{d} 0$, but there were no associations between GHCR $(P=0.24)$ and the interaction between GDPR and GHCR $(P=0.72)$ and estradiol concentration on $\mathrm{d} 0$ (Table 3$)$. There was a tendency $(P=0.10)$ for heifers with high GDPR to be more likely to ovulate within 96 $\mathrm{h}$ of the onset of estrus, but GHCR $(P=0.28)$ and the interaction between GDPR and GHCR $(P=0.52)$ were not associated with the likelihood of ovulation within $96 \mathrm{~h}$ of the onset of estrus (Table 3). Ovulatory follicle size was $(P<0.01)$ larger for high-GDPR heifers than for low-GDPR heifers; conversely, there was a tendency $(P=0.10)$ for high-GHCR heifers to have smaller ovulatory follicles than low-GHCR heifers (Table 3 ). Genomic merit for DPR $(P=0.49)$ and HCR $(P=$ 0.54 ) were not associated with ovulation according to changes in $\mathrm{P} 4$ concentration from d 0 to 7 (Table 3). Concentration of $\mathrm{P} 4$ from $\mathrm{d} 7$ to 14 was not associated with GDPR (high $=3.74 \pm 0.23$, low $=3.52 \pm 0.23 \mathrm{ng} /$ $\mathrm{mL} ; P=0.50)$, GHCR (high $=3.50 \pm 0.23$, low $=3.77$ $\pm 0.24 \mathrm{ng} / \mathrm{mL} ; P=0.44)$, and the interaction between GDPR and GHCR $(P=0.39)$.

\section{Physiological Responses of Heifers Pregnant $38 \pm 3$ d After Estrus According to GDPR and GHCR}

Progesterone concentration on d 0 tended $(P=0.08)$ to be associated with GDPR (high $=0.03 \pm 0.01$, low $=0.01 \pm 0.01 \mathrm{ng} / \mathrm{mL}$ ), but it was not associated with GHCR (high $=0.03 \pm 0.01$, low $=0.01 \pm 0.01 \mathrm{ng} /$ $\mathrm{mL} ; P=0.51)$ and the interaction between GDPR and GHCR $(P=0.36)$. From d 7 to $35, \mathrm{P} 4$ concentration was not associated with GDPR (high $=5.03 \pm 0.37$, low $=5.36 \pm 0.42 \mathrm{ng} / \mathrm{mL} ; P=0.57$ ), GHCR (high $=$ $5.27 \pm 0.33$, low $=5.09 \pm 0.40 \mathrm{ng} / \mathrm{mL} ; P=0.74)$, and the interaction between GDPR and GHCR $(P=0.32)$.

Relative expression of mRNA for ISG15 on d $19 \pm$ 2 was not associated with GDPR (high $=7.26 \pm 0.25$, low $=7.49 \pm 0.33$ fold change; $P=0.60$ ), GHCR (high $=7.48 \pm 0.31$, low $=7.27 \pm 0.36$ fold change; $P=$ 0.68 ), and the interaction between GDPR and GHCR $(P=0.85)$. Concentration of PSPB on $\mathrm{d} 19 \pm 2$ was $(P=0.05)$ associated with GDPR (high $=0.14 \pm 0.01$, low $=0.18 \pm 0.02 \mathrm{ng} / \mathrm{mL})$, but GHCR $(P=0.59)$ and the interaction between GDPR and GHCR $(P=0.18)$ were not associated with PSPB concentrations on d 19 \pm 2 (Figure 1). Concentration of PSPB from d 28 to 35 was $(P=0.03)$ greater for heifers with high GDPR compared with heifers with low GDPR $(3.03 \pm 0.15$ vs. $2.48 \pm 0.19 \mathrm{ng} / \mathrm{mL})$, but GHCR $(P=0.76)$ and the interaction between GDPR and GHCR $(P=0.61)$ were not associated with PSPB concentrations from d 28 to 35 (Figure 1).

Concentrations of IGF-1 on d 0 were not associated with $\operatorname{GDPR}(P=0.25)$, GHCR $(P=0.61)$, and the

Table 3. Association $( \pm \mathrm{SEM})$ among genomic merit for daughter pregnancy rate (GDPR) and genomic merit for heifer conception rate (GHCR) and physiological responses

\begin{tabular}{|c|c|c|c|c|c|c|c|}
\hline Item & \multicolumn{2}{|c|}{ GDPR } & \multicolumn{2}{|c|}{ GHCR } & \multicolumn{3}{|c|}{$P$-value } \\
\hline Progesterone at $\mathrm{PGF}_{2 \alpha}$ treatment, $\mathrm{ng} / \mathrm{mL}$ & $4.58 \pm 0.48$ & $3.37 \pm 0.48$ & $4.22 \pm 0.49$ & $3.75 \pm 0.48$ & 0.08 & 0.51 & 0.71 \\
\hline Detected in estrus, ${ }^{1} \%$ (no.) & $89.6(43)$ & $80.4(41)$ & $91.8(45)$ & $78.0(39)$ & 0.94 & 0.02 & 0.96 \\
\hline Progesterone on $\mathrm{d} 0,{ }^{2} \mathrm{ng} / \mathrm{mL}$ & $0.03 \pm 0.01$ & $0.01 \pm 0.01$ & $0.01 \pm 0.01$ & $0.01 \pm 0.01$ & 0.08 & 0.51 & 0.83 \\
\hline Ovulatory follicle diameter, $\mathrm{mm}$ & $16.3 \pm 0.3$ & $14.6 \pm 0.4$ & $15.0 \pm 0.3$ & $15.8 \pm 0.4$ & $<0.01$ & 0.10 & 0.47 \\
\hline Ovulation according to progesterone, ${ }^{4} \%$ (no.) & $100.0(43)$ & $97.6(40)$ & $97.8(44)$ & $100.0(39)$ & 0.49 & 0.54 & 0.42 \\
\hline
\end{tabular}

${ }^{1}$ Detected in estrus by the automated estrus detection device within $7 \mathrm{~d}$ of $\mathrm{PGF}_{2 \alpha}$ treatment.

${ }^{2} \mathrm{~d}$ 0: sample collected within $24 \mathrm{~h}$ of onset of estrus.

${ }^{3}$ Disappearance of an ovarian follicle $\geq 10 \mathrm{~mm}$ within $96 \mathrm{~h}$ of the first ultrasound exam.

${ }^{4}$ Progesterone concentration $<1 \mathrm{ng} / \mathrm{mL}$ within $24 \mathrm{~h}$ of the onset of estrus and progesterone concentration $\geq 1 \mathrm{ng} / \mathrm{mL} 7 \mathrm{~d}$ later. 

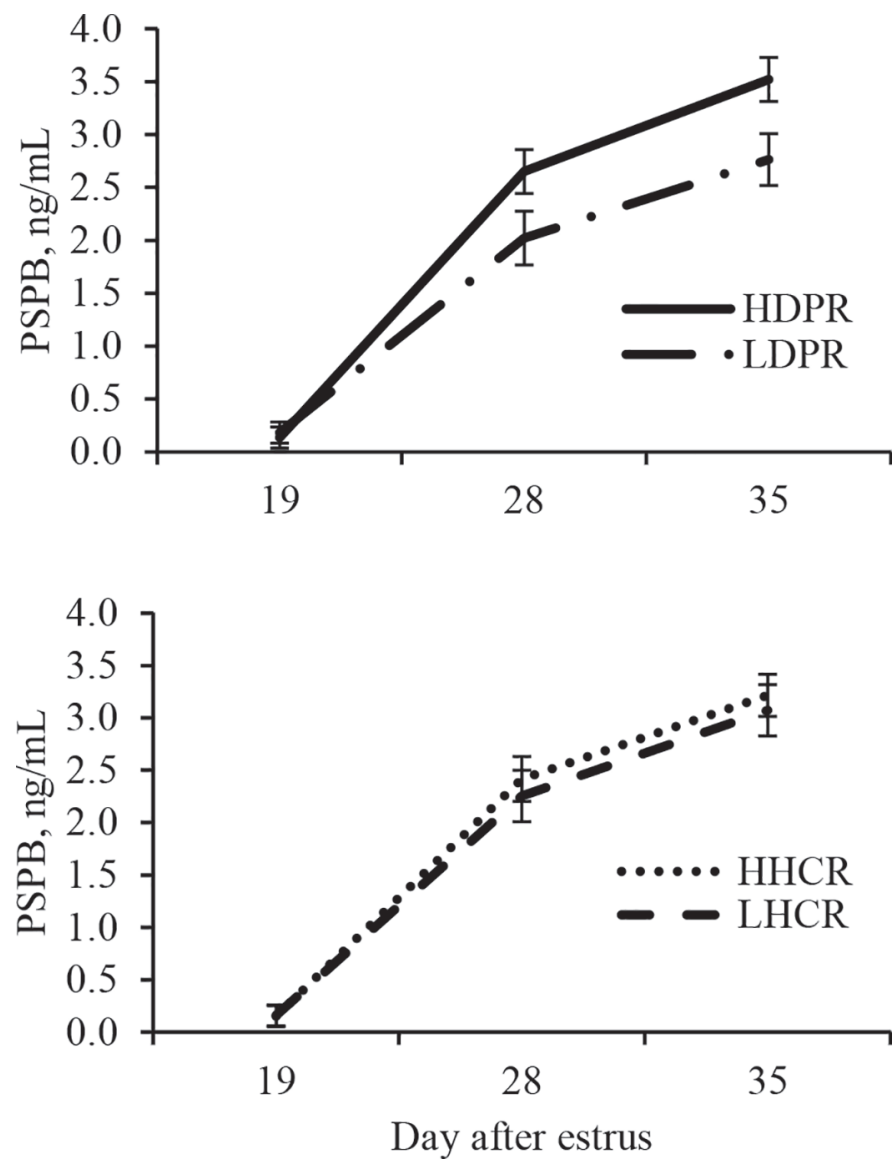

Figure 1. Pregnancy-specific protein B (PSPB) concentration from d $19 \pm 2$ to 35 after estrus among heifers pregnant on d $38 \pm 3$ according to genomic merit for daughter pregnancy rate (GDPR) and heifer conception rate (GHCR). HDPR = high GDPR; LDPR = low GDPR; HHCR $=$ high GHCR; LHCR = low GHCR. Top: association between GDPR and PSPB on d $19 \pm 2(P=0.05)$ and from d 28 to $35(P=$ 0.03). Bottom: association between GHCR and PSPB on d $19 \pm 2(P$ $=0.59)$ and from d 28 to $35(P=0.76)$. Error bars represent SEM.

interaction between GDPR and GHCR $(P=0.14$; Figure 2). From d 7 to 35, GDPR was not $(P=0.69)$ associated with IGF-1 concentration, but heifers with high GHCR tended $(P=0.06)$ to have greater IGF-1 concentration from d 7 to 35 compared with heifers with low GHCR $(108.0 \pm 3.2$ vs. $97.7 \pm 4.2 \mathrm{ng} / \mathrm{mL}$; Figure 2). The interaction between GDPR and GHCR, however, was not $(P=0.18)$ associated with IGF-1 concentration from d 7 to 35 .

\section{DISCUSSION}

The aim of the current study was to provide novel information regarding the associations among fertility traits implemented in genomic selection for the Holstein breed in the past $15 \mathrm{yr}$ and physiological responses that may significantly affect their reproductive performance.
Genomic merit for DPR was associated with greater estradiol concentrations on d 0 , larger ovulatory follicle diameter, and greater likelihood of ovulation within the first $96 \mathrm{~h}$ of onset of estrus. High GHCR, however, tended to be associated with smaller ovulatory follicle diameter. In a companion study, we demonstrated that heifers in the highest quartile for GDPR were detected in estrus faster after a $\mathrm{PGF}_{2 \alpha}$ treatment, had longer estruses, and had more pronounced rumination nadir on the day of estrus than heifers in the lowest quartile for GDPR (Veronese et al., 2019). In the same study, however, GHCR was not associated with characteristics of $\mathrm{PGF}_{2 \alpha}$ synchronized estrus. According to these data, we speculate that GDPR may affect ovarian follicle growth and the steroidogenesis apparatus within ovar-
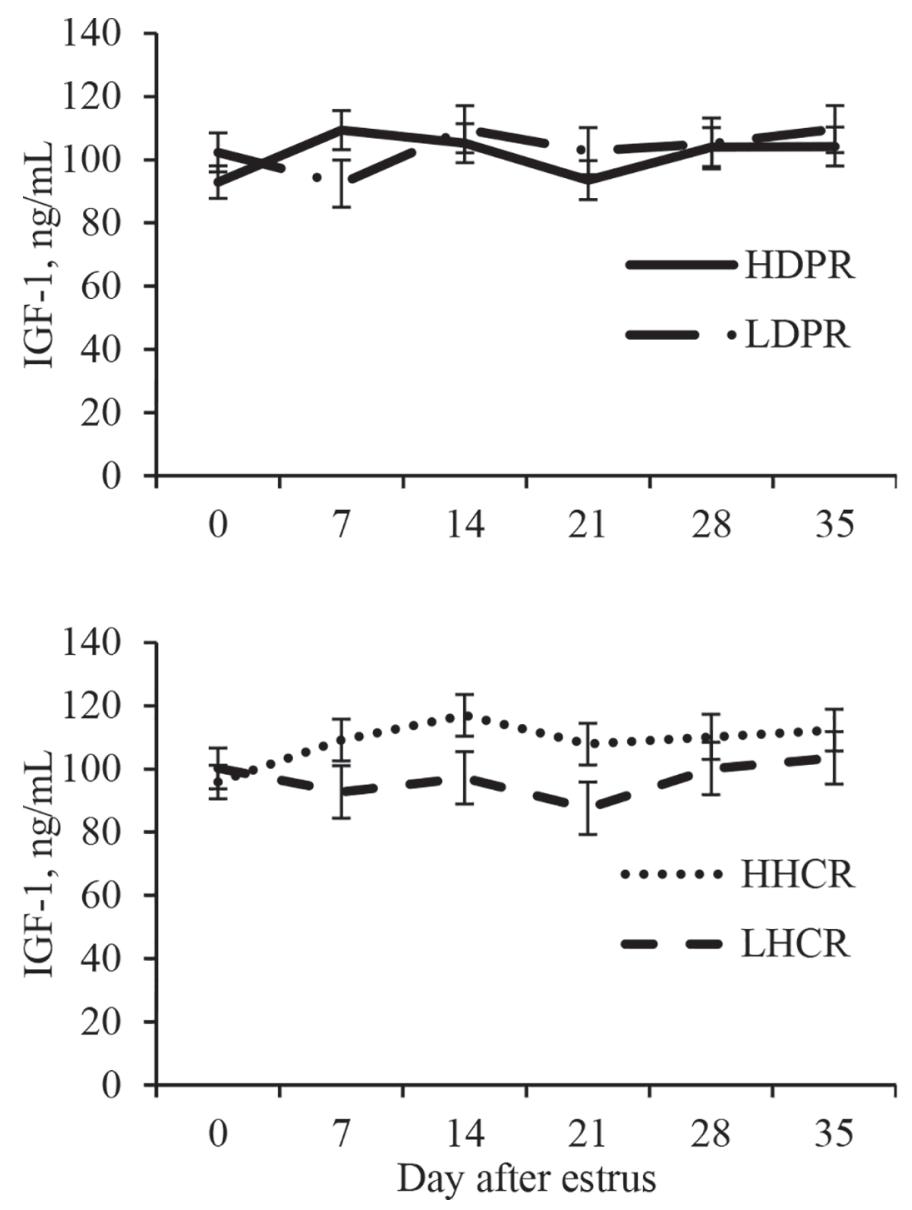

Figure 2. Association among genomic merit for daughter pregnancy rate (GDPR) and heifer conception rate (GHCR) and IGF-1 from d 0 to 35 among heifers pregnant $38 \pm 3 \mathrm{~d}$ after service. HDPR $=$ high GDPR; LDPR = low GDPR; HHCR = high GHCR; LHCR $=$ low GHCR. Top: association between GDPR and IGF-1 on d $0(P$ $=0.25)$ and from d 7 to $35(P=0.69)$. Bottom: association between GHCR and IGF-1 on d $0(P=0.61)$ and from d 7 to $35(P=0.06)$. Error bars represent SEM. 
ian follicles during the proestrus phase. Cummins et al. (2012a) demonstrated that cows with high genetic merit for fertility traits had larger ovulatory follicles and tended to have greater estradiol concentration during proestrus compared with cows with low genetic merit for fertility traits. Cochran et al. (2013) investigated SNP in 1,532 candidate genes believed to be associated with fertility traits in bulls with low PTA for DPR (range: -5.9 to -2 ) and high PTA for DPR (range: 1.7 to 5.3 ). Genes associated with estrogen biosynthesis (HSD17B 7 and HSD17B12) were overrepresented among bulls with high DPR. Both of these genes encode enzymes that convert estrone to estradiol, and $H S D 17 B 7$ is essential for de novo cholesterol synthesis, whereas HSD17B12 is involved in the synthesis of arachidonic acid. In the same study, however, only $H S D 17 B^{7} 7$ was upregulated in bulls with high PTA for HCR. Additionally, the gene ACAT2, which is involved in cholesterol metabolism, was overrepresented in bulls with high PTA for DPR (Cochran et al., 2013). In a follow-up study, the same group demonstrated that of the 39 SNP reported to be related to DPR by Cochran et al. (2013), 19 were associated with DPR in a population of 2,323 cows with low DPR (range: -5.4 to -1.0 ) and high DPR (range: 1.5 to 3.7; Ortega et al., 2016). Of particular importance, Ortega et al. (2016) confirmed that genes important for cholesterol (ACAT2 and HSD17B 7 ) and estrogen (HSD17B7 and HSD17B12) biosynthesis pathways, involved in steroidogenesis, were overrepresented in highDPR cows. Furthermore, 13 genes related to fertility traits were observed to be targets of estrogen regulation (APBB1, BCAS1, CAST, CD40, FST, HSD17B12, HSD17B7, LHCGR, PMM2, OCLN, PGR, RABEP2, and TXN2) and 6 genes related to fertility traits were observed to be targets of $\mathrm{P} 4$ regulation (CD40, EPAS1, $F S T, L H C G R, P G R$, and $O C L N)$. We speculate, therefore, that mechanisms by which selection of dairy cattle for GDPR may improve estrus expression (longer and more intense estruses) are through hastened growth of the preovulatory follicle, improved steroidogenesis, or, less likely, reduced metabolism of steroidal hormones.

There was a positive association between GDPR and $\mathrm{P} 4$ concentration on the day of $\mathrm{PGF}_{2 \alpha}$ treatment and on d 0, but GDPR was not associated with P4 concentrations from $\mathrm{d} 7$ to 14 (all heifers) and from $\mathrm{d}$ 7 to 35 (heifers pregnant on $\mathrm{d} 38 \pm 3$ ). It is important to note that the differences in $\mathrm{P} 4$ concentration on $\mathrm{d}$ 0 were minute and are likely not biologically relevant. Progesterone is produced by luteinized granulosa and theca cells from the ovulated follicle (Forde et al., 2011) and has a crucial role in pregnancy establishment and maintenance (Stevenson and Lamb, 2016). We expected, therefore, that GDPR and GHCR would be associated with greater concentrations of $\mathrm{P} 4$ during diestrus. Cummins et al. (2012a) noted that P4 concentration was particularly greater from d 6 to 13 of diestrus among cows with high versus low genetic merit for fertility traits. In the current study, we only used heifers, whereas Cummins et al. (2012a) used lactating cows, which could explain the disparity in results. Additionally, Ortega et al. (2016) demonstrated that most of the genes related to fertility traits were involved with actions of steroids and, to a lesser extent, $\mathrm{P} 4$.

In the current study, GDPR and GHCR were not associated with expression of mRNA for ISG15 on d $19 \pm$ 2. Heifers with high DPR, however, had greater PSPB concentration from d 28 to 35 compared with heifers with low DPR. Genomic merit for HCR was not associated with PSPB concentrations. In a companion study, we demonstrated that heifers with high DPR were more likely to be pregnant after the first AI compared with heifers with low DPR, whereas GHCR was not associated with pregnancy after the first AI (Veronese et al., 2019). Pregnancy outcome was not the focus of the current study, but we intended to evaluate whether GDPR and GHCR were associated with markers of early embryo and conceptus development. Conceptus development and maintenance are highly dependent on a series of conceptus signaling that must be recognized by the dam (Ribeiro et al., 2014). In ruminants, IFN- $\tau$ produced by the trophoblast stimulates a series of genes that block the luteolytic cascade and prevent regression of the corpus luteum, the so-called maternal recognition of pregnancy (reviewed by Dorniak et al., 2013). Concentrations of IFN- $\tau$ in utero are dependent mainly on the size of the conceptus (Shirasuna et al., 2015). Although it is difficult to measure IFN- $\tau$ in the maternal circulation, IFN- $\tau$ increases the expression of interferon-stimulated genes (e.g., ISG15) by peripheral blood leukocytes, and increased expression of mRNA for ISG15 has been associated with improved embryo and fetal development (Matsuyama et al., 2012; Ribeiro et al., 2014). Similarly, PSPB, secreted by binucleate trophoblastic cells, is associated with conceptus development and pregnancy maintenance in heifers and cows (Humblot et al., 1988; Green et al., 2005). We speculate that the greater estradiol concentration on $\mathrm{d} 0$ and the larger ovulatory follicle improved the endometrial environment of heifers with high GDPR, favoring pregnancy establishment (Madsen et al., 2015).

A surprising finding of our study was that, among heifers pregnant on d $38 \pm 3$, IGF-1 concentration from d 7 to 35 tended to be higher for heifers with high GHCR compared with heifers with low GHCR. Cummins et al. (2012b) demonstrated that cows with higher genetic merit for fertility traits had greater 
IGF-1 concentration during lactation. Additionally, the hepatic mRNA expression of IGF binding proteins 2 , 5 , and 6 were upregulated in cows with low genetic merit for fertility traits around parturition compared with cows with high genetic merit for fertility traits (Cummins et al., 2012b). Considering that IGF binding proteins regulate IGF-1 bioavailability and that IGF-1 has greater affinity to its binding proteins than its receptors (Rajaram et al., 1997; Le Roith et al., 2001; Renaville et al., 2002; Duan, 2002), we speculate that the genetic selection for fertility traits (e.g., HCR) modulates the somatotropic axis by modifying expression and secretion of IGF binding proteins.

\section{CONCLUSIONS}

The greater estradiol concentrations on d 0 and ovulatory follicle size observed among heifers with high GDPR in the current study may explain why high-GDPR heifers have more evident signs of estrus and suggests that continued selection for GDPR could potentially improve estrus detection efficiency and accuracy on farm. Furthermore, we speculate that the greater concentrations of estradiol at estrus observed among high-GDPR heifers may have improved the uterine environment to the extent of improving embryo and conceptus development as observed by the increased PSPB concentrations among them. The association between GHCR and IGF-1 condDISCUSSION intriguing and warrants further investigatio the positive association between IGF-1 an establishment and maintenance.

\section{ACKNOWLEDGMENTS}

The authors thank the owner and ste Florida Holsteins (Bell, FL) for allowing ure swuy and all farm staff for the help provided. Gratitude is extended to SCR Inc. (Netanya, Israel) and Merck Animal Health (Madison, NJ) for partial financial support.

\section{REFERENCES}

AIPL (Animal Improvement Programs Laboratory). 2005. USDA yield evaluation description. Accessed Oct. 1, 2017. https://aipl.arsusda .gov/reference/yield.htm.

AIPL (Animal Improvement Programs Laboratory). 2013. Changes to evaluation system. Accessed Oct. 1, 2017. https://www.uscdcb .com/reference/changes/eval1312.htm.

Cochran, S. D., J. B. Cole, D. J. Null, and P. J. Hansen. 2013. Discovery of single nucleotide polymorphisms in candidate genes associated with fertility and production traits in Holstein cattle. BMC Genet. 14:49-72. https://doi.org/10.1186/1471-2156-14-49.

Cummins, S. B., P. Lonergan, A. C. O. Evans, and S. T. Butler. 2012a. Genetic merit for fertility traits in Holstein cows: II. Ovarian follicular and corpus luteum dynamics, reproductive hormones, and estrus behavior. J. Dairy Sci. 95:3698-3710. https://doi.org/ 10.3168/jds.2011-4976.

Cummins, S. B., S. M. Waters, A. C. O. Evans, P. Lonergan, and S. T. Butler. 2012b. Genetic merit for fertility traits in Holstein cows: III. Hepatic expression of somatotropic axis genes during pregnancy and lactation. J. Dairy Sci. 95:3711-3721. https://doi .org/10.3168/jds.2011-4977.

Dorniak, P., F. W. Bazer, and T. E. Spencer. 2013. Physiology and Endocrinology Symposium: Biological role of interferon tau in endometrial function and conceptus elongation. J. Anim. Sci. 91:1627-1638. https://doi.org/10.2527/jas.2012-5845.

Duan, C. 2002. Specifying the cellular responses to IGF signals: Roles of IGF-binding proteins. J. Endocrinol. 175:41-54.

Forde, N., M. E. Beltman, P. Lonergan, M. Diskin, J. F. Roche, and M. A. Crowe. 2011. Oestrous cycles in Bos taurus cattle. Anim. Reprod. Sci. 124:163-169. https://doi.org/10.1016/j.anireprosci .2010.08.025.

García-Ruiz, A., J. B. Cole, M. Paul, G. R. Wiggans, F. J. Ruiz-López, and P. Curtis. 2016. Changes in genetic selection differentials and generation intervals in US Holstein dairy cattle as a result of genomic selection. Proc. Natl. Acad. Sci. USA 113:E3995-E4004. https://doi.org/10.1073/pnas.1519061113.

Gifford, C. A., M. Assiri, M. C. Satterfield, T. E. Spencer, and T. L. Ott. 2008. Receptor transporter protein 4 (RTP4) in endometrium, ovary, and peripheral blood leukocytes of pregnant and cyclic ewes. Biol. Reprod. 79:518-524. https://doi.org/10.1095/ biolreprod.108.069468.

Green, J. A., T. E. Parks, M. P. Avalle, B. P. Telugu, A. L. McLain, A. J. Peterson, W. McMillan, N. Mathialagan, R. R. Hook, S. Xie, and R. M. Roberts. 2005. The establishment of an ELISA for the detection of pregnancy-associated glycoproteins (PAGs) in the serum of pregnant cows and heifers. Theriogenology 63:1481-1503. https://doi.org/10.1016/j.theriogenology.2004.07.011.

Humblot, F., S. Camous, J. Martal, J. Charlery, N. Jeanguyot, M. Thibier, and R. G. Sasser. 1988. Pregnancy-specific protein B, progesterone concentrations and embryonic mortality during early pregnancy in dairy cows. J. Reprod. Fertil. 83:215-223. https://doi .org/10.1530/jrf.0.0830215.

M., M. F. Smith, J. A. Atkins, K. G. Pohler, G. A. Perry, M acNeil, A. J. Roberts, R. C. Waterman, L. J. Alexander, and . Geary. 2013. Preovulatory estradiol and the establishment naintenance of pregnancy in suckled beef cows. J. Anim. Sci. 76-1185. https://doi.org/10.2527/jas.2012-5611.

D., C. Bondy, S. Yakar, J.-L. Liu, and A. Butler. 2001. The tomedin hypothesis: 2001. Endocr. Rev. 22:53-74.

J., and T. D. Schmittgen. 2001. Analysis of relative gene exion data using real-time quantitative PCR and the $2-\Delta \Delta \mathrm{CT}$ od. Methods 25:402-408. https://doi.org/10.1006/meth.2001

Lucy, M. C. 2001. Reproductive loss in high-producing dairy cattle: Where will it end? J. Dairy Sci. 84:1277-1293. https://doi.org/10 .3168/jds.S0022-0302(01)70158-0.

Madsen, C. A., G. A. Perry, C. L. Mogck, R. F. Daly, M. D. MacNeil, and T. W. Geary. 2015. Effects of preovulatory estradiol on embryo survival and pregnancy establishment in beef cows. Anim. Reprod. Sci. 158:96-103. https://doi.org/10.1016/j.anireprosci 2015.05.006.

Matsuyama, S., T. Kojima, S. Kato, and K. Kimura. 2012. Relationship between quantity of IFNT estimated by IFN-stimulated gene expression in peripheral blood mononuclear cells and bovine embryonic mortality after AI or ET. Reprod. Biol. Endocrinol. 10:2130. https://doi.org/10.1186/1477-7827-10-21.

Mikshowsky, A. A., D. Gianola, and K. A. Weigel. 2017. Assessing genomic prediction accuracy for Holstein sires using bootstrap aggregation sampling and leave-one-out cross validation. J. Dairy Sci. 100:453-464. https://doi.org/10.3168/jds.2016-11496.

Ortega, M. S., A. C. Denicol, J. B. Cole, D. J. Null, and P. J. Hansen. 2016. Use of single nucleotide polymorphisms in candidate genes associated with daughter pregnancy rate for prediction of genetic merit for reproduction in Holstein cows. Anim. Genet. 47:288-297. https://doi.org/10.1111/age.12420. 
Pryce, J. E., M. D. Royal, P. C. Garnsworthy, and I. L. Mao. 2004. Fertility in the high-producing dairy cow. Livest. Prod. Sci. 86:125-135. https://doi.org/10.1016/S0301-6226(03)00145-3.

Rajaram, S., D. J. Baylink, and S. Mohan. 1997. Insulin-like growth factor-binding proteins in serum and other biological fluids: Regulation and functions. Endocr. Rev. 18:801-831.

Renaville, R., M. Hammadi, and D. Portetelle. 2002. Role of the somatotropic axis in the mammalian metabolism. Domest. Anim. Endocrinol. 23:351-360.

Ribeiro, E. S., R. G. S. Bruno, A. M. Farias, J. A. Hernández-Rivera, G. C. Gomes, R. Surjus, L. F. V. Becker, A. Birt, T. L. Ott, J. R. Branen, R. G. Sasser, D. H. Keisler, W. W. Thatcher, T. R. Bilby, and J. E. P. Santos. 2014. Low doses of bovine somatotropin enhance conceptus development and fertility in lactating dairy cows. Biol. Reprod. 90:10-21. https://doi.org/10.1095/biolreprod .113.114694.

Santos, J. E., R. S. Bisinotto, E. R. Ribeiro, F. S. Lima, L. F. Greco, C. R. Staples, and W. W. Thatcher. 2010. Applying nutrition and physiology to improve reproduction in dairy cattle. Soc. Reprod. Fertil. Suppl. 67:387-403.

Shirasuna, K., H. Matsumoto, S. Matsuyama, K. Kimura, H. Bollwein, and A. Miyamoto. 2015. Possible role of interferon tau on the bovine corpus luteum and neutrophils during the early pregnancy. Reproduction 150:217-225. https://doi.org/10.1530/REP-15-0085.
Stevenson, J. S., and G. C. Lamb. 2016. Contrasting effects of progesterone on fertility of dairy and beef cows. J. Dairy Sci. 99:59515964. https://doi.org/10.3168/jds.2015-10130.

USDA. 2016. Daughter pregnancy rate evaluation of cow fertility. Accessed Oct. 1, 2017. https://aipl.arsusda.gov/reference/fertility/ DPR_rpt.htm.

Vandesompele, J., K. De Preter, F. Pattyn, B. Poppe, N. Van Roy A. De Paepe, and F. Speleman. 2002. Accurate normalization of real-time quantitative RT-PCR data by geometric averaging of multiple internal control genes. Genome Biol. 3:34-45. https://doi .org/10.1186/gb-2002-3-7-research0034.

VanRaden, P. M., A. H. Sanders, M. E. Tooker, R. H. Miller, H. D. Norman, M. T. Kuhn, and G. R. Wiggans. 2004. Development of a national genetic evaluation for cow fertility. J. Dairy Sci. 87:22852292. https://doi.org/10.3168/jds.S0022-0302(04)70049-1.

Veronese, A., O. Marques, R. Moreira, A. L. Belli, R. S. Bisinotto, T. R. Bilby, F. Peñagaricano, and R. C. Chebel. 2019. Genomic merit for reproductive traits. I: Estrous characteristics and fertility in Holstein heifers. J. Dairy Sci. 102:6624-6638. https://doi.org/10 .3168/jds.2018-15205.

Yuan, J. S., A. Reed, F. Chen, and C. N. Stewart. 2006. Statistical analysis of real-time PCR data. BMC Bioinformatics 7:85-96. https://doi.org/10.1186/1471-2105-7-85. 